\title{
Diel behavior of sardine and anchovy schools in the California Current System
}

\author{
Amanda M. Kaltenberg*, Kelly J. Benoit-Bird \\ College of Oceanic and Atmospheric Sciences, Oregon State University, 104 COAS Administration Building, Corvallis, \\ Oregon 97331, USA
}

\begin{abstract}
Fish schools containing Pacific sardine Sardinops sagax and northern anchovy Engraulis mordax were observed in 2 regions within the California Current System in 2 years using a combination of moored and shipboard acoustics and net sampling. Schools of sardines and anchovies off the Oregon coast followed typical diel patterns consistent with antipredator behavior, dispersing at nighttime, rapidly reforming into discrete schools at sunrise, and maintaining schooling behavior throughout daylight hours. Discrete schools containing primarily sardines in Monterey Bay, California, were observed during both daytime and nighttime in addition to layers and loose aggregations at nighttime, with a peak in the formation of schools occurring several hours before sunrise. Transitions between daytime and nighttime behaviors occurred more gradually in Monterey Bay than off the Oregon coast. The 2 regions experienced different prey environments, with acoustic indices for zooplankton abundance in Monterey Bay much higher than off Oregon. Due to the shallower water column, prey availability was fairly consistent throughout day and night in Monterey Bay. However, prey availability was highly variable at the Oregon site, where diurnally migrating zooplankton were only available to fish in the surface region at night. The combined effects of prey availability and the water column depth may influence the efficiency of school formation, leading to the differences in diel patterns of schooling that were observed among the 2 regions. These environmental influences on schooling behavior likely have significant consequences for predators that rely on sardine and anchovy schools as prey as well as the commercial fisheries in both regions.
\end{abstract}

KEY WORDS: Schooling $\cdot$ Behavior $\cdot$ Sardine $\cdot$ Anchovy $\cdot$ Predator-prey relationship $\cdot$ Zooplankton · Fisheries · Acoustics

\section{INTRODUCTION}

In coastal upwelling regions, wind-driven upwelling brings nutrient-rich waters to the surface, which can support enhanced primary productivity as compared to other coastal or oceanic biomes (Huyer 1983). In the major coastal upwelling regions of the world, small pelagic schooling fish are an ecologically and commercially important group that serves as important prey for larger fish, marine mammals, and seabirds (Brodeur et al. 2005, Emmett et al. 2005). Sardines Sardinops spp. and anchovies Engraulis spp., 2 dominant fish species in upwelling ecosystems, are generalist planktonic grazers that feed on phytoplankton, copepods, and euphausiids, and are significant consumers of both pri- mary and secondary production (Lasker 1970, Robinson 2000, Cunha et al. 2005, Emmett et al. 2005).

Sardines and anchovies are obligate schoolers, meaning they spend most of their lives swimming in coherently organized schools (Breder 1967). Fish schools, like those observed in sardines and anchovies, display synchronized and polarized behavior, making them one type of aggregated social assemblage, more generally referred to as fish shoals (Pitcher \& Parrish 1993). Schooling fish generally display a behavior of forming into dense schools during the day and dispersing at night (Azzali et al. 1985, Fréon et al. 1996, Fréon \& Misund 1999, Cardinale et al. 2003). This diel behavior is believed to be regulated by a balance between the pressures of predation and the needs of individuals 
to eat. Nighttime dispersal may also benefit schooling fish by decreasing predation by nocturnal predators (Radakov 1973). Nocturnal predators that do not rely on vision for prey detection have an increased predation rate on schooling fish when they are aggregated in schools than when they are dispersed (Pitcher \& Parrish 1993). Schooling may also be hindered by decreased light level at nighttime in some species that rely on vision to maintain orientation within the group. Anchovy, however, are able to maintain schooling at very low light levels (O'Connell 1963, Hunter \& Nicholl 1985), and saithe Pollachius virens are able to school with no light relying solely on lateral line senses (Pitcher et al. 1976).

The specific forces driving the formation and dispersal dynamics of schools are not well understood, with a number of studies reaching contradictory results regarding the rate of school dispersal and formation at dusk and dawn. Azzalli et al. (1985) modeled the diel patterns of schooling and suggested that nighttime school dispersion is sudden, while the reforming of schools at dawn is a gradual process. In situ acoustic observations of schools by Fréon et al. (1996) indicated the opposite pattern, that school dispersal at nighttime is slow, whereas the dawn reformation was rapid. Weston \& Andrews (1990) also observed rapid dispersal at dusk with more gradual formation at dawn, but found seasonal shifts in timing and speed of dispersal and formation linked to seasonal light patterns. The combined results of previous experiments have lead to the hypothesis that the dynamics of school formation and dispersal are driven by a combination of factors that may include light, prey density, and individual fish energy requirements. For example, once individuals have eaten enough so that foraging is no longer their top priority during nighttime, individuals may rejoin a group as a refuge from predation (Radakov 1973), assuming the low light level permits for schooling. The amount of time fish choose to spend in aggregated or dispersed behavior during dark hours may therefore be a function of prey density in addition to predation risk, as food availability determines how much effort must be expended for effective foraging.

The purpose of the present study was to investigate the diel patterns of pelagic fish schooling behavior by quantifying the timing and rate of school formation and dispersal relative to prey availability. The west coast of the United States is adjacent to the California Current System, an eastern boundary current driven by coastal upwelling, and supports large populations of small, pelagic schooling fish usually dominated by Pacific sardine Sardinops sagax and northern anchovy Engraulis mordax. Fishery grounds on the west coast of the United States are generally located adjacent to processing facilities. To target the areas of high ecolog- ical and commercial interest, the present study took place in 2 of these major fishery grounds, 1 near Monterey, California, and 1 off Astoria, Oregon. Continuous observations with moored and shipboard acoustics of fish schools and mesozooplankton prey provided extensive information on school behavior. These acoustic observations were supplemented with oceanographic measurements. Data from bottommounted, upward-looking acoustic moorings may provide advantages over sampling from shipboard spatial survey data alone (Axenrot et al. 2004). (1) Bottommounted moorings are able to provide data from the depth region very near the surface that is within the blind zone of hull-mounted transducers, typically at least 3 to $5 \mathrm{~m}$. A significant portion of small schools may be located entirely within this zone. (2) Potential ship-avoidance behaviors observed in other studies (Soria et al. 1996, Fréon \& Misund 1999, Vabø et al. 2002) are eliminated since moorings are mounted on the seafloor at a distance from the targeted animals. (3) Moorings can be easily deployed and recovered from small boats that need to visit the site only once at the beginning and end of the study period, providing extended data sets that might not be possible to collect otherwise. However, stationary moorings alone cannot measure the horizontal dimension of fish schools. We have combined moored and shipboard acoustic data to investigate the temporal and spatial patterns of school behavior, providing information on schooling behavior that would not be available by either method alone.

\section{MATERIALS AND METHODS}

Data collection. Fish schools were acoustically observed in a northern and southern region of the California Current System in 2005 and 2006 (Fig. 1). The northern site, near the mouth of the Columbia River between the border of Oregon and Washington, was studied in August 2005 and June 2006. The Oregon/Washington coast is characterized by relatively simple topography, a narrow shelf, and a straight coastline. Wind conditions in summer are generally upwelling-favorable with brief relaxation events between upwelling and downwelling conditions (Huyer 1983). The southern site was located in Monterey Bay, California, and was studied in July 2005 and July to August 2006. Monterey Bay is a large, shallow bay with the exception of a long, deep canyon running through the center. Commercial purse seine fishing for sardines occurs on the shallow shelf regions of the bay. Like the Oregon coast, in the summer months (March to $\mathrm{Au}$ gust), hydrology and circulation in Monterey Bay is characterized by wind-driven upwelling conditions. Circulation within the bay is also influenced by bathy- 


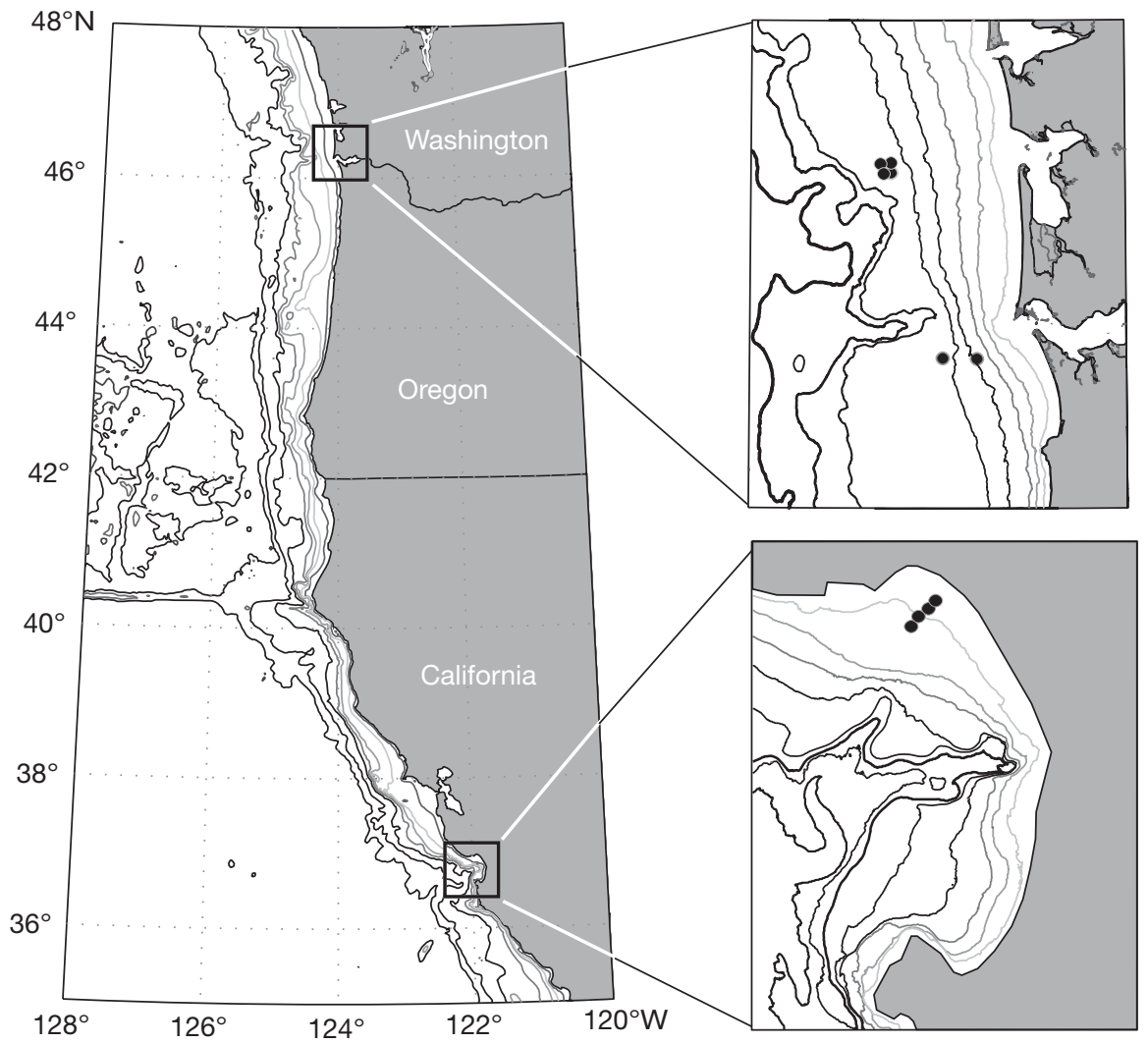

Fig. 1. The 2 study regions in the California Current Systems showing the 50, 100, 200, 500, 1000, 2000, and 5000 m isobaths. Insets: Oregon/Washington and Monterey Bay study regions showing the placement of acoustic moorings $(\bullet)$ and the 20, 40, 60, $80,100,200,500,1000$, and $2000 \mathrm{~m}$ isobaths

metric upwelling due to the interaction of flow and the canyon walls and the advection of cold, upwelled water from the adjacent region to the north outside of the bay (Rosenfeld et al. 1994, Graham \& Largier 1997). Local study sites within each region were selected in areas of high fish abundance based on either predeployment surveys or the location of high fishing efforts at the time. Bottom-mounted $200 \mathrm{kHz}$ bio-acoustic moorings, Water Column Profilers (WCPs) (ASL Environmental Sciences), were deployed in either a straight line or a box pattern during each study (Fig. 1). The WCPs had a $3 \mathrm{~dB}$ beamwidth of $10^{\circ}$. The pulse rate and vertical bin size of WCPs were set to maximize the resolution for each study length and water depth (Table 1). Each WCP was attached directly to sandbag anchors so that the transducer was approximately $1 \mathrm{~m}$ off the seafloor, with substantial floatation under the transducer to keep the instrument stable. This stability was confirmed using readings from a logging tilt and roll sensor in each instrument. No floats or lines were deployed above the instrument package to limit unintended acoustic returns and the aggregation of fish that is sometimes observed around surface floats. Recovery of each WCP was accomplished using acoustic releases that permitted the instrument package to float to the surface and be retrieved, sacrificing the sandbag anchors.

Table 1. WCP mooring data collection. Instrument frequency $200 \mathrm{kHz}$, pulse length $156 \mu \mathrm{s}$

\begin{tabular}{|lccccccc|}
\hline Region & Year & Date & $\begin{array}{c}\text { Deployment } \\
\text { duration } \\
\text { (d) }\end{array}$ & $\begin{array}{c}\text { No. of } \\
\text { moorings }\end{array}$ & $\begin{array}{c}\text { Water depth } \\
(\mathrm{m})\end{array}$ & $\begin{array}{c}\text { Pulse } \\
\text { rate } \\
(\text { Hz) }\end{array}$ & $\begin{array}{c}\text { Vertical bin } \\
\text { resolution } \\
(\mathrm{m})\end{array}$ \\
\hline Monterey Bay & 2005 & Aug 9-Sep 14 & 35 & 1 & 21 & 0.08 & 0.125 \\
Monterey Bay & 2006 & Jul 12- Jul 29 & 17 & 4 & $16.4,17.8,18.9,20.5$ & 0.25 & 0.125 \\
Oregon & 2005 & Aug 9-Aug 25 & 16 & 2 & 75,110 & $0.016,0.06$ & 0.125 \\
Oregon & 2006 & Jun 2- Jun 7 & 5 & 4 & $118,123,125,131$ & 0.25 & 0.25 \\
\hline
\end{tabular}


Table 2. Shipboard spatial surveys data collection. Instrument frequencies $38 / 120 \mathrm{kHz}$, pulse lengths $256 / 64 \mu \mathrm{s}$, respectively

\begin{tabular}{|lccc|}
\hline Region & Year & Date & Ship \\
\hline Monterey Bay & 2005 & Aug 20 to Sep 8 & RV 'New Horizon' \\
Monterey Bay & 2006 & Jul 11 to Aug 9 & RV 'Thomas Thompson' \\
Oregon & 2005 & Aug 23 to Aug 26 & FV 'Frosti' \\
Oregon & 2006 & Jun 2 to Jun 7 & FV 'Frosti' \\
\hline
\end{tabular}

Shipboard spatial surveys were conducted both day and night in Monterey Bay and primarily during the daytime for Oregon sampling. Surveys were conducted surrounding the area of each mooring array using split-beam Simrad EK60 echosounders at 38 and $120 \mathrm{kHz}$ (Table 2) surveying at speeds between 3 and 5 knots. The $120 \mathrm{kHz}$ transducer had a $7^{\circ}$ conical beam and the $38 \mathrm{kHz}$ transducer had a $12^{\circ}$ conical beam. Transducers were mounted $1 \mathrm{~m}$ below the surface using a rigid pole mount over the side of the RV 'New Horizon' in Monterey Bay in 2005 and over the side of the RV 'Thomas Thompson' in Monterey Bay in 2006. Transducers were mounted on a towfish that was towed approximately $1 \mathrm{~m}$ below the surface alongside the fishing vessel FV 'Frosti' during the Oregon 2005 and 2006 sampling. All echosounders were calibrated using an indirect procedure incorporating a $38.1 \mathrm{~mm}$ diameter tungsten carbide reference sphere as prescribed by Foote et al. (1987).

Daytime fish sampling was conducted by collaborators from the Northwest Fisheries Science Center during the Oregon study in 2005 and 2006 from the FV 'Frosti' near the WCP moorings as part of a study integrating acoustic and net trawl sampling (Brodeur unpubl. data). A Nordic 264 rope trawl (12 m deep $\times$ $28 \mathrm{~m}$ wide) (Net Systems) was towed at the surface astern the vessel at $1.5 \mathrm{~m} \mathrm{~s}^{-1}$ for $30 \mathrm{~min}$ per tow. Mesh size of the net ranged from $162.6 \mathrm{~cm}$ at the mouth to $8.9 \mathrm{~cm}$ at the cod end. Abundance data of small schooling species collected from net samples taken at sampling stations within $25 \mathrm{~km}$ of the moorings were used for ground-truthing and interpretation of the acoustic data.

Fish sampling by conventional net tows was not possible in Monterey Bay. However, alternative methods were employed to provide as much quantitative information as possible on fish species composition near the study site. Commercial fishery landings in California are documented in detail in the Fish Bulletin Series of the Division of Fish and Game of California (http:// www.dfg.ca.gov). Monthly data for the Monterey region were used to quantify commercial landings of pelagic schooling fish species. Results of the dominant species are reported as a percentage of the total bio- mass of all pelagic schooling species including northern anchovy Engraulis mordax, Pacific herring Clupea pallasi, Pacific mackerel Scomber japonicus, jack mackerel Trachurus symetricus, Chinook salmon Oncorhynchus tshawytscha, and Pacific sardine Sardinops sagax. Visual observations were also made during acoustic survey cruises of schooling fish very near the surface and in the mouths of diving seabirds and sea lions. Visual observations were made at sampling intervals of 5 min during all daytime sampling by an individual experienced with identifying fish species found in Monterey Bay. Finally, daily interviews were conducted during 2006 sampling with local purseseine fishermen as they returned to shore. They provided daily information on the location of fishing efforts, the species caught, and the timing of their fishing efforts.

Zooplankton net tows took place during daytime and nighttime in both years of Monterey Bay sampling and for the 2006 Oregon sampling. In 2005, sampling off Oregon took place during daytime only. Samples were collected using either a $0.5 \mathrm{~m}$ diameter vertically towed net $(200 \mu \mathrm{m}$ mesh) from $100 \mathrm{~m}$ to the surface in deep water or $5 \mathrm{~m}$ off the bottom (when water depth was $<100 \mathrm{~m}$ ), or a Bongo Net (200 $\mu \mathrm{m}$ mesh) towed obliquely. Plankton samples were preserved in $10 \%$ buffered formalin and later counted for relative abundance measurements of each species or lowest possible taxonomic group in the lab, except during the Oregon 2006 study when Bongo plankton samples were frozen and later thawed and immediately preserved in $10 \%$ buffered formalin before being sorted in the lab.

Local times for day and night categorizations were based on the time of sunrise and sunset provided by the US Naval Observatory database. Transition periods, within $1 \mathrm{~h}$ of sunrise and sunset, were not included in daytime or nighttime periods. Data on moon phase was also used and was provided by the US Naval Observatory database. Fraction of the moon's face illuminated was used to characterize nighttime illumination (i.e. 1 = full moon, 0 = new moon).

Acoustic characterization of fish schools. Data from the 38 and $120 \mathrm{kHz}$ shipboard echosounders and from the stationary $200 \mathrm{kHz}$ WCPs were used to characterize school behavior. Acoustical schools, characterized as acoustically unresolved multiple fish or plankton aggregations and with discrete edges (Kieser et al. 1993), are strong acoustic scattering targets with a broad frequency response observable at both 38 and $200 \mathrm{kHz}$. Acoustic schools were detected using a modified method of the schools detection module (Barange 1994) in Echoview software (Myriax Software). To de- 
tect fish schools, first a minimum threshold criterion of $-60 \mathrm{~dB}$ was applied to all data to remove low-intensity targets and noise. Then, to determine if a potential acoustical patch was a school, it needed to meet length and height criteria (if from shipboard data) or a comparable duration and height criteria (from WCP mooring data). For shipboard data, acoustic schools exceeded a minimum length of $5 \mathrm{~m}$ and a minimum height of $2 \mathrm{~m}$. Schools that were not connected by adjacent bins but were very close to each other were considered one school if the horizontal distance separating them was less the $6 \mathrm{~m}$ ('max horizontal linking distance' in Echoview) and the vertical distance was less than $3 \mathrm{~m}$ ('max vertical linking distance'). Finally, a potential school made up of combined linked schools was considered a positive detection if the school had a total horizontal dimension of at least $10 \mathrm{~m}$ ('minimum total length') and total vertical dimension of $5 \mathrm{~m}$ ('minimum total height'). Data from stationary WCPs represents time and depth rather than distance and depth, as in shipboard data. The duration that a school can be detected in the acoustic beam depends on the size of the school and the speed of movement through the beam. To detect schools in stationary WCP data, the same vertical criteria were used as with shipboard data (minimum of $2 \mathrm{~m}$ ), but duration was used instead of the length measurements of shipboard data for the horizontal parameters. To be classified as a school, an aggregation must have exceeded a minimum duration equivalent to $24 \mathrm{~s}$, horizontal linking distance must have been less than $12 \mathrm{~s}$, vertical linking distance less than $3 \mathrm{~s}$, and total horizontal duration was at least $18 \mathrm{~s}$ and total vertical distance was at least $5 \mathrm{~s}$.

These criteria settings for shipboard and stationary data were selected to include all true fish schools including small schools. Fish schools in echograms can be visually characterized as strong scattering features with discrete and continuous edges, and are distinct from dispersed aggregations of fish or layers of fish (Fig. 2). Efforts were made to avoid false positive detections of schools in the data by visually searching through all of the detected schools in the echograms. Schools that were suspected of false positive detections such as those that did not have discrete edges were categorized as layers or loose aggregations and were not included in the analysis. Schools that had skewness or kurtosis values significantly different from the mean (greater than the mean $\pm 95 \%$ confidence interval) were excluded from the analysis. Similarly, attempts were made to include incorrectly missed schools that did not meet the automated detection criteria. Again, the acoustic echograms were visually searched for suspected missed schools. If a suspected school was consistent with the acoustic characteristics of a true fish school defined above, it was manually defined as a school region using Echoview's region tool and analyzed along with other detected schools.

Each identified school was characterized by several parameters: date and time of the school, lunar phase as percent of moon illumination for that date and location, depth of school, water column depth, skewness, kurtosis, school NASC (nautical area scattering coefficient, which is the integrated acoustic backscatter from within the school in units of square meters per square nautical mile $\left(\mathrm{m}^{2} \mathrm{nmi}^{-2}\right)$, school length (for schools detected from EK60 surveys), and duration of the school (for schools detected by WCPs). School length measurements were used as a description of school behavior, since school expansion generally occurs more in the horizontal plane rather than in the vertical or omnidirectional for most clupeoids (Blaxter \& Hunter 1982, Soria et al. 2003, Zwolinski et al. 2007). School length measurements were based on the start and end difference of GPS position from shipboard surveys corrected to account for beam width, as suggested by Diner (2001). For schools smaller than the width of the beam, the uncorrected lengths were used since correction could lead to negative values. Similarly, duration for schools detected by the moored instruments was based on the start and end time of each school and was corrected for changes of beam width with depth, using:

$$
\begin{gathered}
\text { Corrected school duration }=\left(t_{\text {start }}-t_{\text {end }}\right) /[2 \times \text { depth } \\
\text { mean of school } \times \tan (\theta / 2)]
\end{gathered}
$$

where $t$ is time and $\theta$ is the $3 \mathrm{~dB}$ beamwidth of the echosounder, which in this case was $10^{\circ}$. The rate of school formation and dissolution were calculated based on the difference between the mean number of schools observed at one hour and the previous hour for each study.

Acoustic characterization of zooplankton. Zooplankton prey abundance was measured acoustically using mooring data from each study. Acoustic backscatter from schools, as well as regions consistent with fish but not defined as schools including layers or fish aggregations, were subtracted from the total signal. High intensity backscatter near the surface corresponding to air bubbles as afternoon winds picked up were observed in Monterey Bay (Holliday \& Greenlaw 2008). The signal was usually within $1 \mathrm{~m}$ of the surface and was subtracted from the total signal. Relative abundance data, nautical area scattering coefficient (NASC), were binned into hourly intervals and integrated over $20 \mathrm{~m}$ vertical depth bins. Since fish schools were primarily observed in the upper $20 \mathrm{~m}$ only, the upper layer was used to quantify the availability of zooplankton to fish for the Oregon site. For the Monterey Bay site, the entire water column was integrated since the water depth was near $20 \mathrm{~m}$.

Hourly chlorophyll sampling took place in Monterey Bay in 2005 near the WCP mooring and in 2006 near 2 

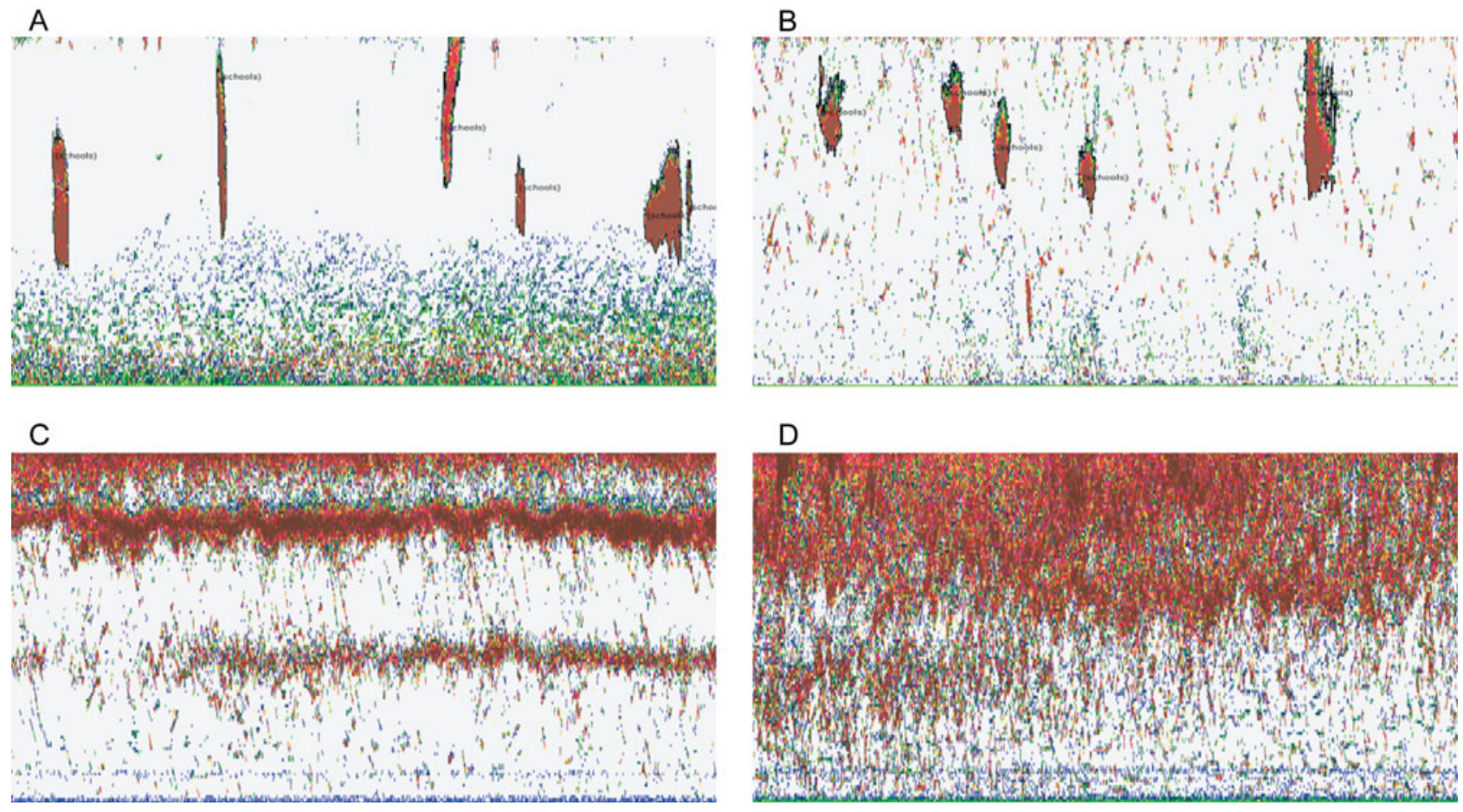

Fig. 2. Echograms of fish. Each panel represents $1 \mathrm{~h}$ of time ( $x$-axis) for data collected from WCP acoustic moorings in Monterey Bay over the water column depth of $20 \mathrm{~m}$ (y-axis) and shows a different fish behavior. (A) Daytime fish schools (observed from local time 11:00 to $12: 00 \mathrm{~h})$; (B) nighttime fish schools $(02: 00$ to 03:00 h); $(\mathrm{C})$ layered fish behavior $(22: 00$ to $23: 00 \mathrm{~h})$; and (D) dispersed aggregation of fish (23:00 to 00:00 h)

of the 4 WCP mooring stations using an autonomous bottom-up profiler (Donaghay 2004, Sullivan \& Donaghay unpubl. data). Chlorophyll samples were integrated from $0.5 \mathrm{~m}$ water depth below the surface to the seafloor $(<20 \mathrm{~m})$. Daytime and nighttime integrated chlorophyll samples were compared to assess the relative availability of phytoplankton prey to foraging fish.

Statistical analysis. Descriptive parameters of each school detected from shipboard surveys and acoustic moorings were analyzed using statistical analysis software (SPSS). To investigate the diel patterns of schools observed, the number of schools detected was binned into hourly counts (schools $\mathrm{h}^{-1}$ ) based on the start time for each school. The effect of hour of the day (24), site (Monterey Bay, Oregon), and year $(2005,2006)$ on the number of schools detected per hour (schools $\mathrm{h}^{-1}$ ) was tested using an ANOVA model:

$$
\text { Schools } \mathrm{h}^{-1} \sim \text { Site }+ \text { Year }+ \text { Hour }
$$

The characteristics of schools were described by testing the schools $\mathrm{h}^{-1}$ against the mean hourly school length (m) obtained from shipboard data, mean hourly school duration (s) from acoustic mooring data, and mean hourly school area scattering [NASC $\left(\mathrm{m}^{2} \mathrm{nmi}^{-2}\right)$ ] from acoustic mooring data using a generalized leastsquares model:
Schools $\mathrm{h}^{-1} \sim$ Length + Duration + NASC

+ Length:Duration + Length:NASC + Duration:NASC

+ Length:Duration:NASC

A linear regression analysis was used to test the relationship between lunar phase and schools $\mathrm{h}^{-1}$ during nighttime hours for both sites and years.

\section{RESULTS}

\section{Fish species composition}

The 7 daytime fish trawls that were collected by collaborators in 2005 near the moorings showed that northern anchovy Engraulis mordax were numerically the most abundant species ( $76 \%$ of the total fish catch) followed by $16 \%$ Pacific sardine Sardinops sagax, and $2 \%$ Pacific herring Clupea pallasii (Brodeur unpubl. data). In 2006, 7 daytime trawls near the moorings indicated that northern anchovy (45\%) and Pacific sardine $(46 \%)$ were the dominant fish species and present in nearly equal abundances.

Commercial fish landings for August and September, 2005, in Monterey Bay indicated that sardines were the dominant species, representing $85 \%$ of the 
total catch of pelagic schooling fish by weight. Pacific herring were second at $9 \%$, and northern anchovy was third at $3 \%$. Visual observations of schools at the surface and being foraged on by seabirds and sea lions supported these landings data, with the dominant fish species in Monterey Bay during 2005 sampling being Pacific sardine. Interviews with commercial purse seine fishermen targeting fish schools in the area of Monterey Bay adjacent to the moorings confirmed that they were also catching both sardines and anchovies.

In 2006 Pacific sardine was the dominant species landed in Monterey Bay in July and August at the time of this study, representing $72 \%$ of the total catch of schooling by weight. Northern anchovy was second at $26 \%$, while Pacific herring was third at $2 \%$. Observations and interviews were also in agreement with landing data that Pacific sardines were dominant over Northern anchovy by about 3 to 1 numerically.

\section{Hourly patterns of schooling}

Acoustic schools consistent with sardine or anchovy schools were observed almost exclusively in the upper $20 \mathrm{~m}$ of the water column at the Oregon site (depth 75 to $130 \mathrm{~m}$ ). Acoustic aggregations that were not consistent with sardine or anchovy schools based on their frequency response from shipboard data were typically observed near bottom during day and vertically migrated to the surface and dispersed at night. These schools were stronger acoustic targets at $120 \mathrm{kHz}$ than $38 \mathrm{kHz}$, and likely represent krill swarms and were omitted from the analysis of fish schools. Acoustic schools of fish in Monterey Bay were observed throughout the water column (depth $<21 \mathrm{~m}$ ). Very low differences in the mean skewness and kurtosis were observed between daytime and nighttime schools for both sites and in both years indicating that the criteria used for defining acoustic schools resulted in statistically similar schools between years and over the daily cycle. An ANOVA test for a difference in means of school skewness on data pooled into 3 categories, day, night, and transition hours, found no significant difference in school skewness $(\mathrm{df}=2$, sum of squares $=0.67$, mean square $=0.34, F=0.55, \mathrm{p}=0.58$ ).

The frequency of schools detected (schools $\mathrm{h}^{-1}$ ) for each hour of the day determined from acoustic moorings for each study is shown in Fig. 3. An ANOVA for the effects of site, year, and hour on the number of schools indicated that hour of the day had a signifi-

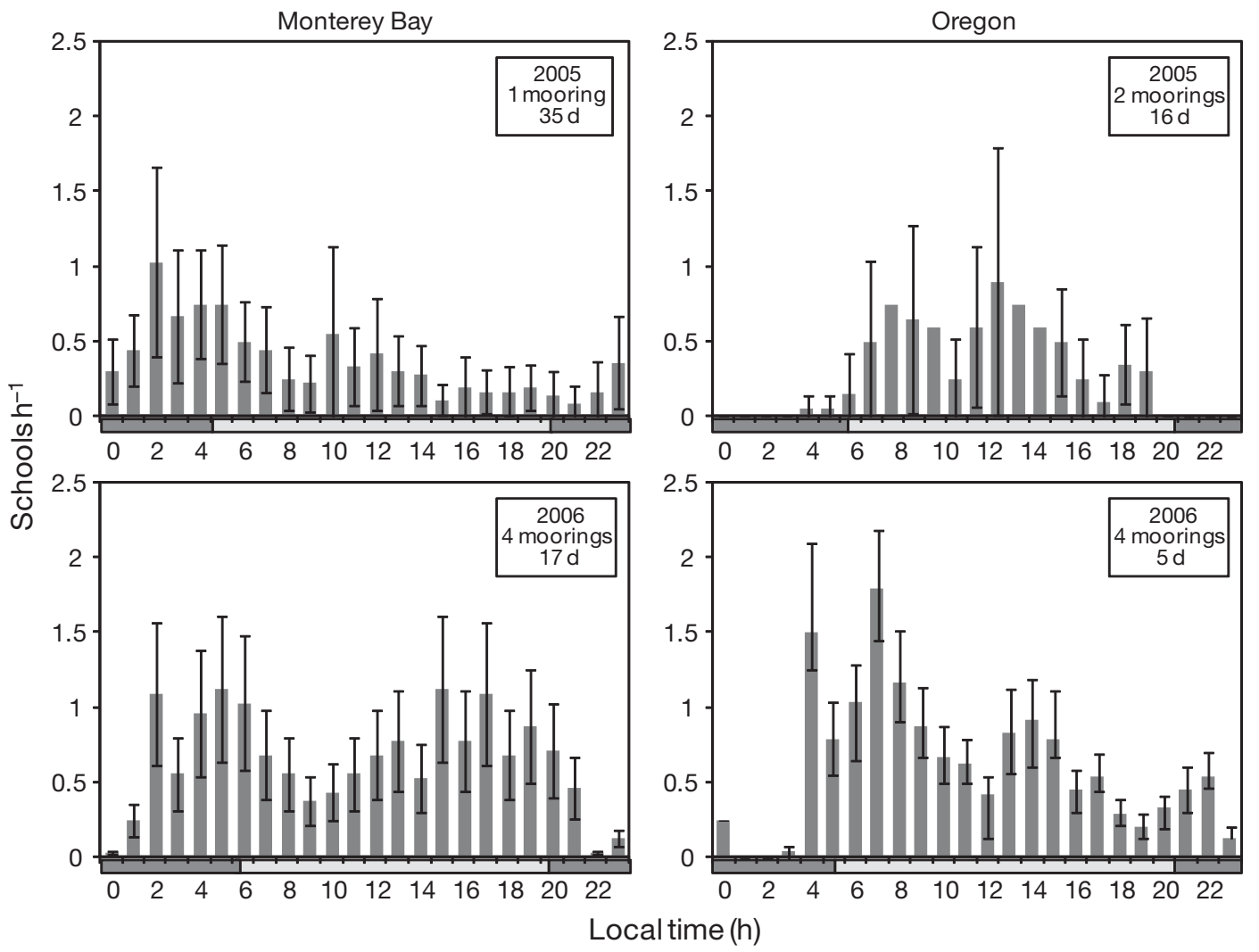

Fig. 3. Mean number of schools $\mathrm{h}^{-1}$ detected during each study $\pm 95 \%$ CI. Local sunrise and sunset times are indicated by the bars along the $x$-axis 
cant effect on schools $\mathrm{h}^{-1}$ in all 4 studies $(\mathrm{p}<0.001)$. In Monterey Bay, the peak number of schools was observed from $02: 00$ to $05: 00 \mathrm{~h}$ local time in both years, with a secondary peak observed at 15:00 $\mathrm{h}$ in 2006. The hour during the peak formation of schools is based on the change in the number of schools observed from one hour to the next (Fig. 3). The period of the greatest formation of schools was $02: 00 \mathrm{~h}$ local time in both 2005 and 2006. The number of schools generally decreased throughout the day in 2005, while in 2006 a secondary peak in school formation was observed in the afternoon at 15:00 $\mathrm{h}$ and then dispersed after sunset.

The Oregon acoustic mooring sampling in 2005 observed almost no schools at night. The period of greatest school formation at 07:00 $\mathrm{h}$ coincided with the timing of sunrise, and the greatest period of school dispersal occurred at 21:00 h, just after sunset. In 2006 off Oregon, a similar pattern of school formation was observed, with the peak of school formation occurring the hour before sunrise at 04:00 $\mathrm{h}$ and declining throughout the daylight hours with a minimum between 01:00 $\mathrm{h}$ and 03:00 h local time. Again, relatively few fish schools were observed at night off Oregon.

To explore the diel characteristics of schools, the number of schools $\mathrm{h}^{-1}$ observed $(\mathrm{n}=24)$ was tested for a correlation between the mean length, duration, and integrated backscatter NASC of schools using a generalized least-squares model including each parameter and their interactions (Table 3). Schools were not observed during many nighttime hours in mooring data in Oregon, so only hours where there were enough schools observed were tested for an effect (primarily daytime hours). No significant effects of school length, duration of schools, and integrated school NASC were found on the number of schools for the Oregon observations. Schools were observed during all hours in Monterey Bay in both years. A significant negative effect of mean school length was found on the number of schools $\mathrm{h}^{-1}$ in 2005, indicating that as more schools were observed they tended to cover less horizontal distance and when fewer schools were observed the schools were larger horizontally. School length each hour of the day from shipboard acoustic surveys in each study is shown in Fig. 4. In 2006 in Monterey Bay, duration showed a significant negative relationship with schools $\mathrm{h}^{-1}$, indicating that when a greater number of schools were observed, their duration over the moorings was shorter. The mean duration of schools from moorings in each hour of the day is shown in Fig. 5. In Monterey Bay 2006 sampling, there was also significant interaction between duration and school NASC. The mean hourly NASC per school observed by acoustic moorings is shown in Fig. 6 for each study.

A linear regression analysis indicated that schools $\mathrm{h}^{-1}$ between local sunset and sunrise times was not significantly related to the moon phase in Monterey Bay ( $p=0.35$ in 2005, 0.31 in 2006). Not enough nighttime schools were observed during Oregon observations for an analysis of lunar illumination effects on schools.

\section{The prey environment}

Zooplankton from Monterey Bay were numerically dominated by copepods (Table 4). The most abundant genera were Calanus, Ctenocalanus, and Arcartia (mean body length \pm SD in $\mathrm{mm}: 1.35 \pm 0.27,0.88 \pm 0.09$, $0.95 \pm 0.07$, respectively). Zooplankton off Oregon had a similar composition, being dominated by copepods during daytime including Acartia and Clausocalanus (mean length $\pm \mathrm{SD}$ in $\mathrm{mm}: 1.23 \pm 0.20,1.33 \pm 0.23$, respectively) (Table 4). However, nighttime samples in 2006 also included several Euphausia pacifica (mean length $10.33 \mathrm{~mm}, \mathrm{SD}=6.8$ ).

Table 3. Generalized least-squares test for effects on the number of schools $\mathrm{h}^{-1}$ observed during each study. School length was measured from shipboard surveys. Duration and school NASC were measured from acoustic moorings. ${ }^{*}$ Significant test results. $\mathrm{df}=$ degrees of freedom. Schools were not detected during several nighttime hours during Oregon sampling, limiting the degrees of freedom to hours when schools were detected

\begin{tabular}{|c|c|c|c|c|c|c|c|c|}
\hline & \multicolumn{4}{|c|}{ - Oregon- } & \multicolumn{4}{|c|}{ _Monterey Bay } \\
\hline & \multicolumn{2}{|c|}{$\begin{array}{l}2005 \\
\mathrm{df}=6\end{array}$} & \multicolumn{2}{|c|}{$\begin{array}{c}2006 \\
\mathrm{df}=17\end{array}$} & \multicolumn{2}{|c|}{$\begin{array}{c}2005 \\
\mathrm{df}=24\end{array}$} & \multicolumn{2}{|c|}{$\begin{array}{c}2006 \\
\mathrm{df}=24\end{array}$} \\
\hline & Coefficient & $\mathrm{p}$ & Coefficient & $\mathrm{p}$ & Coefficient & $\mathrm{p}$ & Coefficient & $\mathrm{p}$ \\
\hline Intercept & 1.71 & 0.40 & 0.11 & 0.98 & 2.23 & 0.08 & 5.79 & $0.02^{*}$ \\
\hline Length & -0.03 & 0.43 & -0.01 & 0.96 & -0.19 & $0.02^{*}$ & -0.15 & 0.52 \\
\hline Duration & 0.00 & 0.39 & 0.00 & 0.99 & 0.00 & 0.64 & -0.06 & $0.01^{*}$ \\
\hline NASC & 0.00 & 0.83 & 0.01 & 0.68 & -0.01 & 0.26 & -0.02 & 0.07 \\
\hline Length:Duration & 0.00 & 0.63 & 0.00 & 0.98 & 0.00 & $0.03^{*}$ & 0.00 & 0.39 \\
\hline Length:NASC & - & - & 0.00 & 0.98 & 0.00 & 0.12 & 0.00 & 0.77 \\
\hline Duration:NASC & - & - & 0.00 & 0.73 & 0.00 & 0.53 & 0.00 & $0.03^{*}$ \\
\hline Length:Duration:NASC & - & - & 0.00 & 0.94 & 0.00 & 0.09 & 0.00 & 0.67 \\
\hline
\end{tabular}




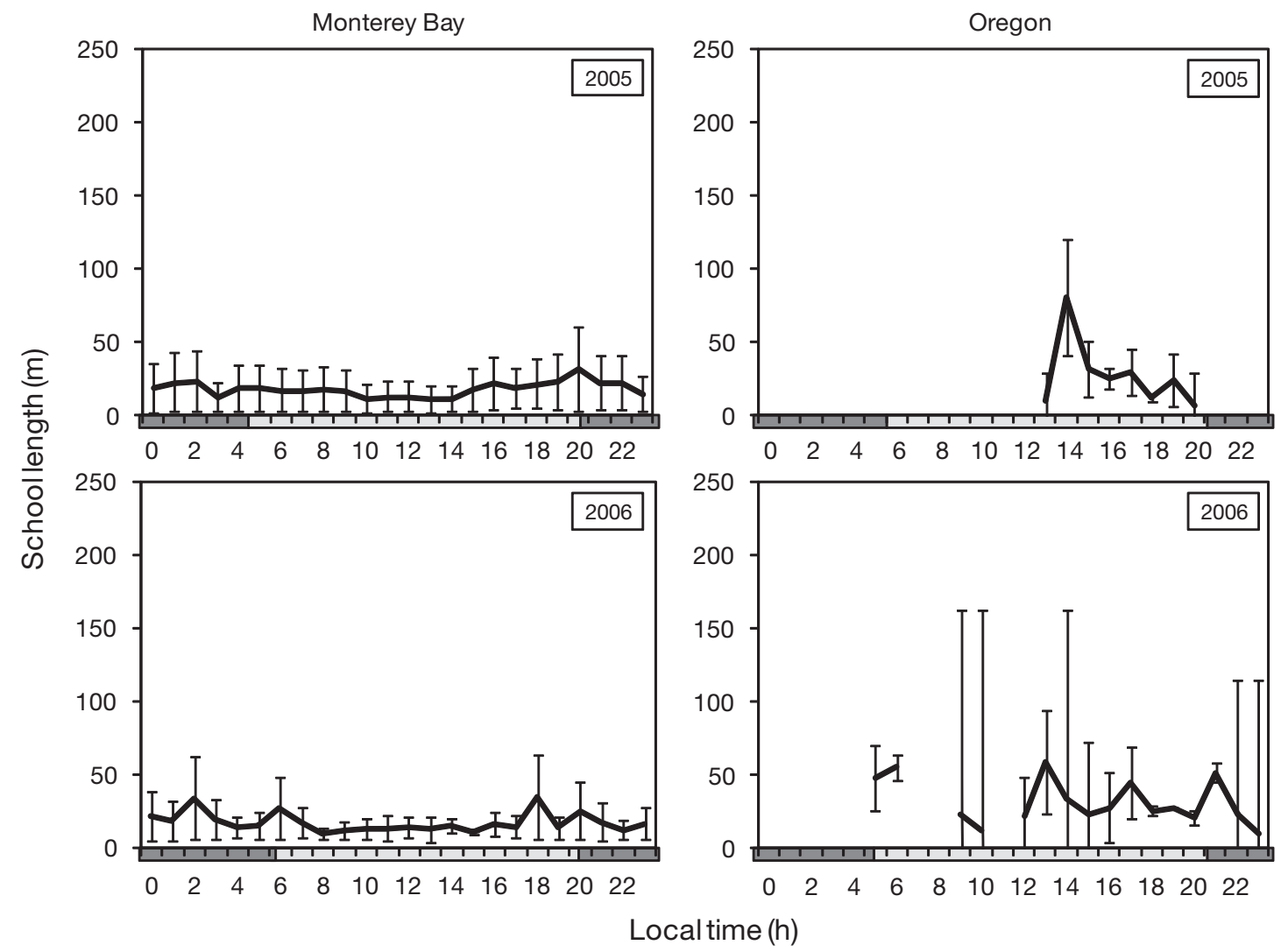

Fig. 4. Mean school length $\pm 95 \%$ CI collected from shipboard spatial surveys. Local sunrise and sunset times are indicated by the bars along the $x$-axis

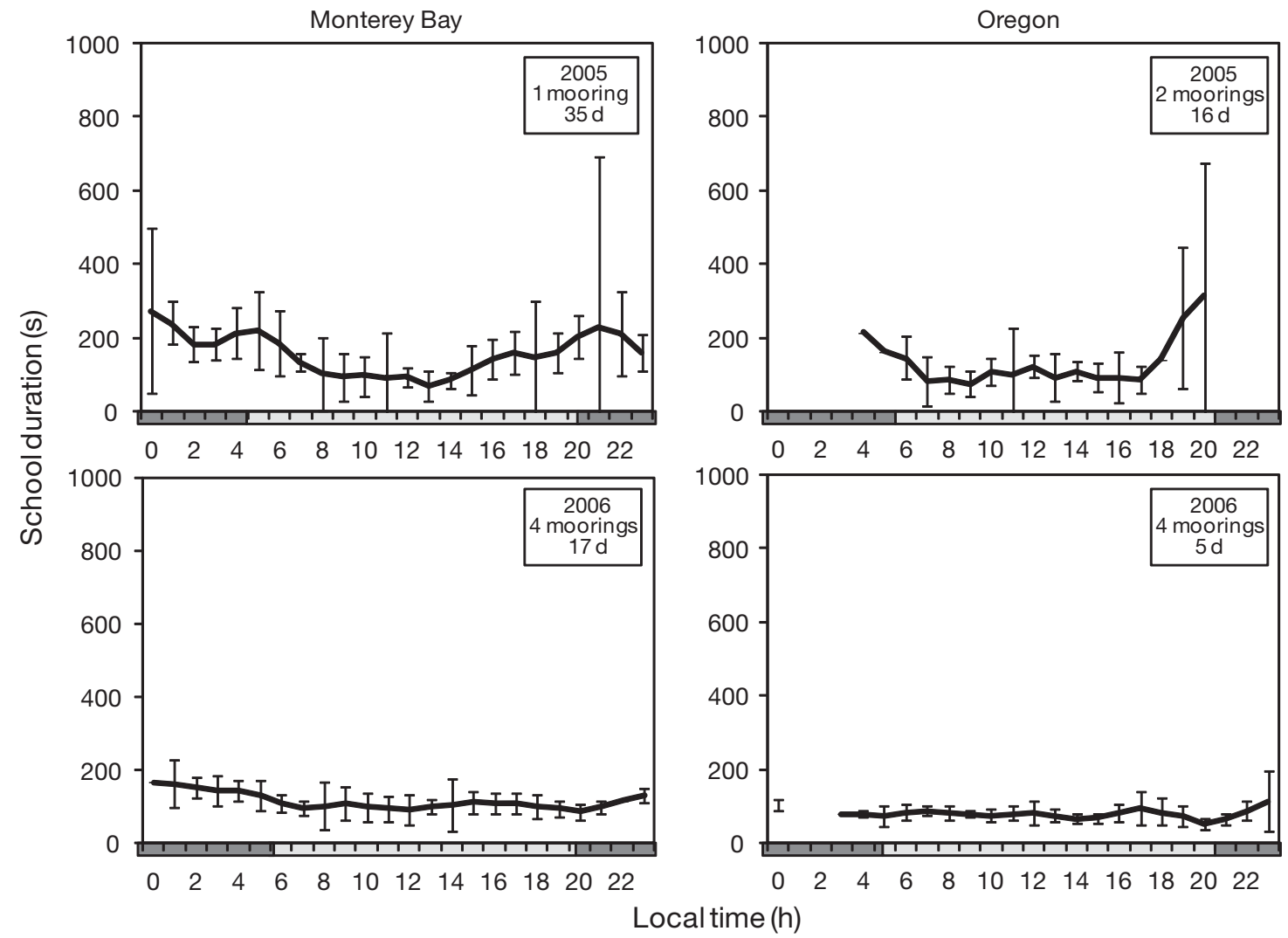

Fig. 5. Mean school duration (s) detected over stationary moorings $\pm 95 \%$ CI. Duration calculations where corrected for changes of beam diameter with depth. Local sunrise and sunset times are indicated by the bars along the $x$-axis 


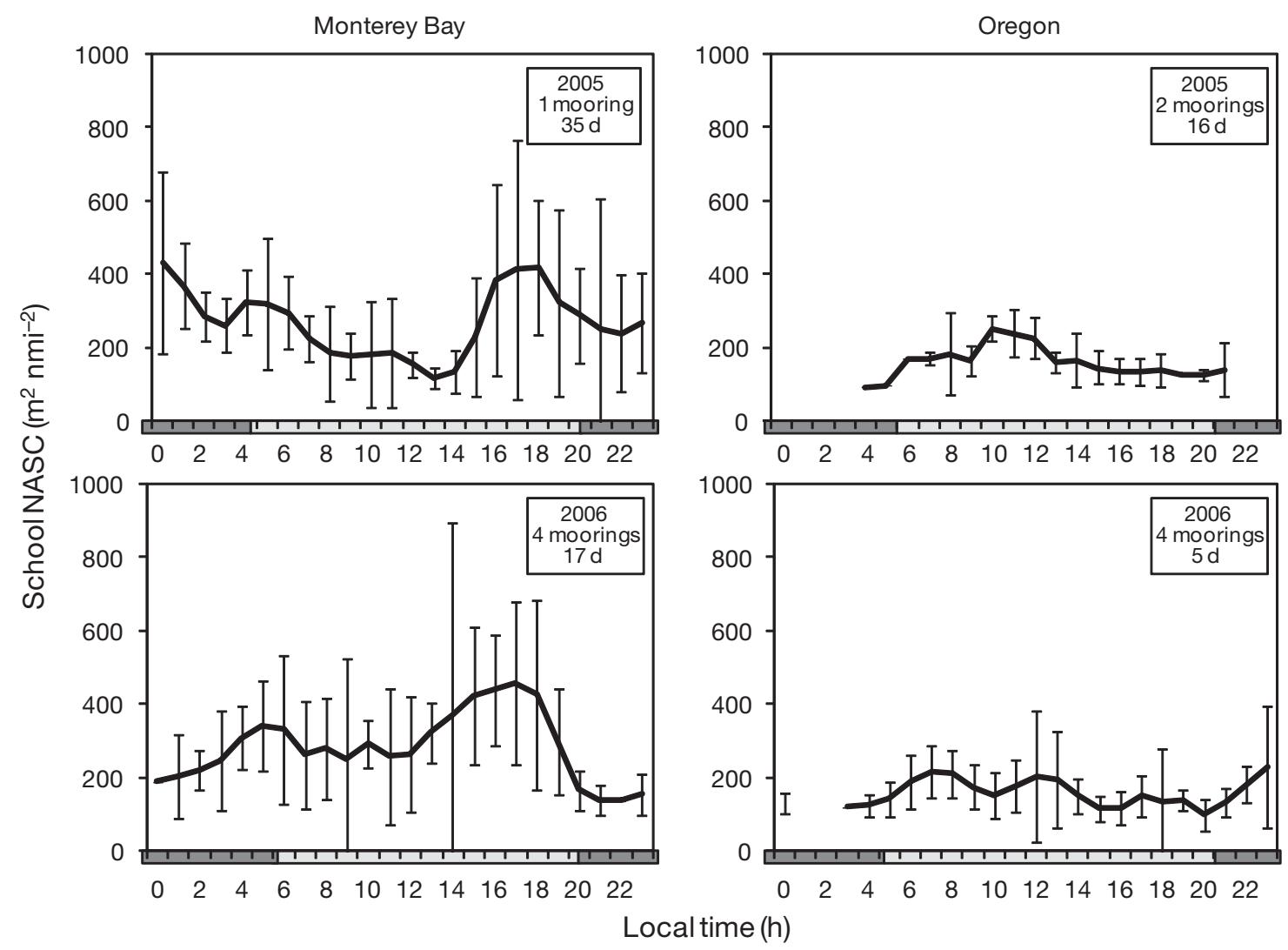

Fig. 6. Mean school nautical area scattering coefficient (NASC) $\pm 95 \%$ CI. Local sunrise and sunset times are indicated by the bars along the $x$-axis

Table 4. Mesozooplankton sampling; note: in Oregon in 2006 individuals were captured using a bongo net

\begin{tabular}{|c|c|c|c|c|}
\hline \multirow[t]{2}{*}{ Zooplankton taxa } & \multicolumn{4}{|c|}{ Daytime (nighttime) individuals $\mathrm{m}^{-3}$} \\
\hline & $\begin{array}{c}\text { Oregon } 2005 \\
n=2(0)\end{array}$ & $\begin{array}{c}\text { Oregon } 2006 \\
\mathrm{n}=11\end{array}$ & $\begin{array}{c}\text { Monterey Bay } 2005 \\
\mathrm{n}=8 \text { (13) }\end{array}$ & $\begin{array}{c}\text { Monterey Bay } 2006 \\
\mathrm{n}=10(2)\end{array}$ \\
\hline Calanoid copepods & $2427.7(-)$ & $608.7(593.8)$ & $132.5(364.6)$ & 587 (1411.5) \\
\hline Acartia & $980.4(-)$ & $99.2(78.8)$ & $19.0(126.3)$ & $17.4(3.6)$ \\
\hline Calanus & $51.3(-)$ & $391.1(352.3)$ & $58.4(1.9)$ & $262.6(110.5)$ \\
\hline Clausocalanus & & $98.1(159.7)$ & $2.2(0.64)$ & $263.5(758.8)$ \\
\hline Psuedocalanus & $189.1(-)$ & & $2.1(108.8)$ & \\
\hline Augaptilidae & $10.0(-)$ & & & \\
\hline Juvenile calanoid copepods & $955.2(-)$ & $17.9(1.8)$ & $125.4(105.4)$ & $43.5(534.2)$ \\
\hline Cyclopodia copepods & $615.3(-)$ & $1.9(1.2)$ & $19.4(6.4)$ & $67.6(76.1)$ \\
\hline Oithonia & $615.3(-)$ & $1.9(1.2)$ & $18.7(3.6)$ & $67.6(76.1)$ \\
\hline Poecilostomatoida & & $1.1(0.7)$ & $9.8(11.6)$ & $0.2(0)$ \\
\hline Copilia & & & $9.8(0)$ & \\
\hline Corycaeus & & $1.1(0.7)$ & $0(11.6)$ & $0.2(0)$ \\
\hline Cladocerans & & $2.6(4.2)$ & $0(6.2)$ & $113.5(159.3)$ \\
\hline Euphausia & $127.1(-)$ & $36.2(71.9)$ & $36.0(29.5)$ & $6.3(37.1)$ \\
\hline E. pacifica, adult & & $12.0(15.1)$ & & \\
\hline E. pacifica, juvenile & $103.9(-)$ & $24.2(56.7)$ & & $6.3(37.1)$ \\
\hline Thysanoessa spinifera, juvenile & $23.2(-)$ & & & \\
\hline Chaetognatha & $3.3(-)$ & $2.6(1.5)$ & $0.25(13.6)$ & $2.8(1.8)$ \\
\hline Crab zoea & & $0(0.1)$ & $33.7(6.6)$ & \\
\hline Appendicularia & & $0.2(0.4)$ & $5.3(116.3)$ & $26(89.6)$ \\
\hline Calycophoran siphonophore & & $27.1(24.3)$ & $7(51.6)$ & \\
\hline Pteropoda & & $55.0(62.1)$ & $0.6(1.4)$ & $0.3(0.9)$ \\
\hline
\end{tabular}


Analysis of mesozooplankton abundance from acoustic mooring data revealed diel vertical migration towards the surface at night and towards the seafloor at day in both sites (Fig. 7). The mean acoustic scattering from zooplankton was higher at night than day for all 4 studies, based on an ANOVA test to compare means between the pooled daytime and nighttime intervals with transition periods excluded $(\mathrm{p}<0.001)$.
The shift between daytime and nighttime abundance in Oregon was very distinct and coincided with sunrise and sunset (Fig. 8). In Monterey Bay, the shift between daytime and nighttime abundance was more gradual (Fig. 8). Assessment of the timing of the vertical migration of prey out of or into the surface waters was based on the greatest positive or negative change in zooplankton abundance from one hour to the next (Fig. 8).
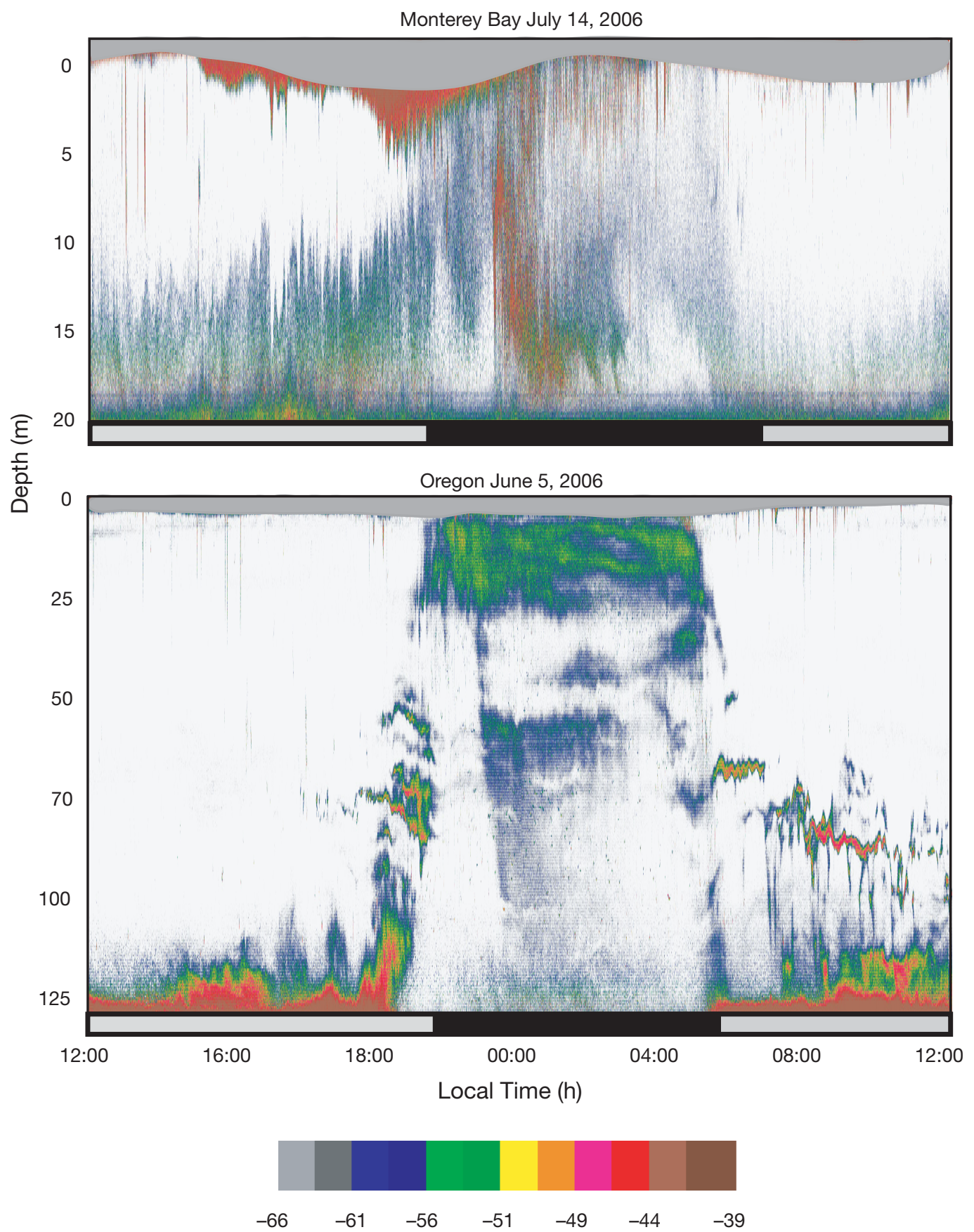

Fig. 7. Representative daily echogram of acoustic backscatter from WCP moorings for each study site. Note the different water depths. Local sunrise and sunset times are indicated by the bars along the $x$-axis 


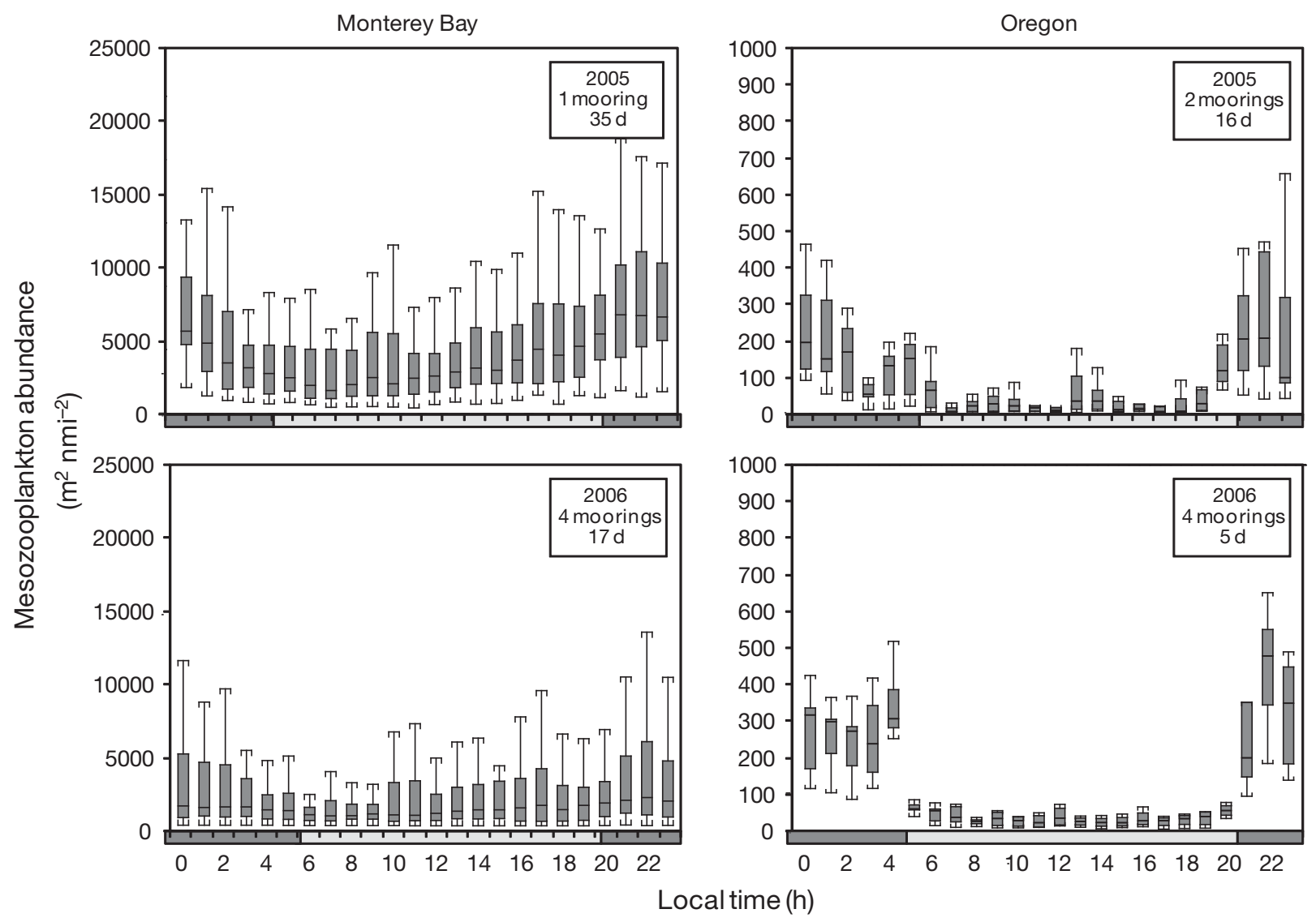

Fig. 8. Mesozooplankton abundance (NASC) in the upper $20 \mathrm{~m}$ of the water column for each study $\pm 95 \%$ CI

In Monterey Bay in 2005, the greatest decrease of zooplankton acoustic scattering corresponding with the diel migration out of the surface waters occurred at 03:00 h local time with the greatest increase occurring at 21:00 h. In Monterey Bay in 2006, the greatest decrease in zooplankton abundance occurred twice during the morning, at 01:00 $\mathrm{h}$ and 05:00 $\mathrm{h}$, with the ascending migration at 21:00 $\mathrm{h}$. The timing and the intensity of these diel patterns of zooplankton were more distinct at the Oregon site where the water column was deeper. In 2005, the greatest decrease in zooplankton occurred at 04:00 $\mathrm{h}$ and increase peaked at 21:00 h. In Oregon in 2006, the descending migration out of the surface occurred at 05:00 h, with the ascending migration at 21:00 $\mathrm{h}$.

Hourly, vertically integrated chlorophyll data was collected during Monterey Bay sampling only (Sullivan \& Donaghay unpubl. data). Binned daytime and nighttime chlorophyll data indicated that there was a significant difference between daytime and nighttime water-column integrated chlorophyll based on a $t$-test with higher concentrations observed during daytime in both years $\left(t_{\text {two-way }}=1.97, \mathrm{p}<0.001\right.$ for 2005 ; $t_{\text {critical }}=$ 1.97, $\mathrm{p}<0.001$ for 2006).

\section{DISCUSSION}

\section{Diel patterns of schooling}

Analysis of the diel patterns of fish behavior in Monterey Bay and Oregon revealed that schools dispersed and reaggregated throughout the diel cycle at both sites, although there was variability in the timing and rates of these behaviors between sites and years. Acoustic observations of schooling at the Oregon site detected almost no schooling at night. During night hours, layers or loose fish aggregations were also not observed, and single targets consistent with small pelagic fish were dispersed both horizontally and vertically throughout this upper region of the water column. The formation of schools at dawn and their dispersal at dusk were rapid processes that generally took place within an hour of the local sunrise and sunset. Rapid dispersal of schooling fish beginning close to sunset has been described previously (Azzali et al. 1985, Axenrot et al. 2004, Zwolinski et al. 2007). Diel schooling in Oregon was consistent with the traditional view for obligate schoolers, in which daytime fish schools expand at nighttime resulting from a release of 
predation by visual predators (Radakov 1973, Parrish \& Hamner 1997). During night, while fish were highly dispersed, zooplankton abundance was several orders of magnitude higher in the upper $20 \mathrm{~m}$ than during the day due to the strong effect of diel vertical migrations of zooplankton.

Fish schools in Monterey Bay also displayed diel formation and dispersal with the peak in formation and the number of schools occurring 3 to $4 \mathrm{~h}$ before sunrise. The formation and dispersal of schools appeared to occur more gradually in Monterey Bay than at the Oregon site. Distinct schools were often observed at nighttime, and, when dispersed, fish were generally aggregated in layers or loose groups that could still be defined as aggregations but did not meet our conservative criteria for schools. Fréon et al. (1996) observed a similar pattern of sardine diel behavior, with limited dispersal of schools at night resulting in aggregations with highly skewed distributions of cross-sectional area and volume backscattering coefficient as compared to daytime schools. The number of schools observed here was linked to the average length of schools, as well as to the combined effects of length and duration in Monterey Bay in 2005, implying a change in average swimming speed as schools broke up into a greater number of smaller schools. In 2006, when more schools were detected, they tended to have shorter duration times over the moorings. Shorter duration times could be expected when observing either smaller schools or schools that are swimming at greater speeds. Our results from Monterey Bay suggest that as schools broke up into a greater number of smaller schools, they also tended to swim at faster swimming speeds. We did not find significant relationships between the number of schools and school length or duration for the Oregon study, likely due to lack of schooling at nighttime and the rapid transitions that prevented gradients in these relationships from being resolved. For each hour, schools tended to be either present or absent, and average schooling characteristics such as length were fairly constant throughout daytime hours.

The 2 sites studied here differ substantially in water depth, which may provide a possible explanation for the differences in schooling behavior. The Oregon site was much deeper than the typical vertical range of schools, which were generally within the upper $20 \mathrm{~m}$ of the water column. The study site in Monterey Bay was only about $20 \mathrm{~m}$, which may have restricted individuals from dispersing more vertically. We speculate that the combined effects of greater abundance of individuals in Monterey Bay and constrained water depth may have facilitated organization of individuals into schools because they were in closer proximity.

The availability of prey likely influenced schooling behavior. A diel pattern in mesozooplankton prey in
Monterey Bay was observed with higher abundances at night (Fig. 8). This pattern was likely due to the migration of organisms very near the bottom and below the instrument about $2 \mathrm{~m}$ off the seafloor (Axenrot et al. 2004). However, the water was too shallow to allow diel vertical migrations of zooplankton to have a significant influence on the availability to fish. Fish schools were observed throughout the water column, and at times particularly large schools were observed spanning the entire water column. So even if zooplankton vertically migrated to the bottom at the Monterey Bay site, they were likely still accessible to schooling fish in the lower portion of the water column. Diel differences were also observed in vertically integrated chlorophyll concentrations in Monterey Bay. However, these changes were due to reverse diel vertical migrations of dinoflagellates over short distance near the surface that was typically above the vertical range of the instrument used $(<3 \mathrm{~m}$ ) (Cheriton et al 2009). These small movements of phytoplankton may influence availability to foraging fish, especially if fish avoid the very near surface area because of high predation by seabirds.

The availability of zooplankton at the Oregon site had a much stronger diel pattern than those observed in Monterey Bay (Fig. 8). The daytime vertical migrations to near the bottom at the Oregon site allowed zooplankton to descend out of the daytime range of fish schools, which were primarily observed in the upper $20 \mathrm{~m}$. These zooplankton migrations were very distinct, with the timing corresponding to sunrise and sunset. Echograms indicated that most of the zooplankton biomass typically migrated to lower regions of the water column and were occasionally observed as layers.

Schooling behavior by small pelagic fish increases foraging encounters on heterogeneous prey patches (Pitcher \& Parrish 1993). However, when the water depth allows for zooplankton to avoid schooling predators by diel vertical migration out of surface waters, the foraging advantages associated with schooling may be decreased or absent. Searching by schooling fish for patches of prey that vertically migrate would be more advantageous at night when their habitats overlap. South Pacific jack mackerel Trachurus murphyi have displayed 'atypical' schooling behavior, with schooling at night and dispersing during day in order to take advantage of vertically migrating mesopelagic prey during their foraging migration along the Chilean coast (Bertrand et al. 2006). We observed only a slight diel variability in the availability of mesozooplankton prey in Monterey Bay, but schooling at nighttime or early morning hours could provide an advantage for foraging when prey were heterogeneously distributed as observed in these other studies. 
Both sites observed here contained mix-species assemblages primarily containing sardines and anchovies. The proportion of each species present varied by site and year. Sardines were numerical dominant in Monterey Bay in both years. Anchovies only made up about $25 \%$ of the total small pelagic species catch in 2006 and $3 \%$ in 2005, with herring making up $9 \%$. Trawl sampling in Oregon indicated that anchovy were relatively more common during our sampling periods, with anchovies being the dominant species in 2005; while in 2006 sardines and anchovies were present in nearly equal abundances. These differences in species composition could suggest different foraging behaviors. Forage fish are able to shift between filter feeding and particle feeding modes in different prey environments, and their diets have linked with the ambient prey concentrations (James 1987, Cunha et al. 2005, Garrido et al. 2008). Schooling fish can filter feed while swimming in schools, but schooling fish have been observed dispersing and disorientating with neighboring fish when shifting to particulate feeding (James \& Findlay 1989, Garrido et al. 2007). The shift between these behaviors is initiated at different particle sizes for each species. Sardines filter feed on prey items between 4 and $724 \mu \mathrm{m}$ and start particulate feeding on prey items $>780 \mu \mathrm{m}$, while anchovies filter feed on prey between 93 and $710 \mu \mathrm{m}$ and particulate feed on prey $>720 \mu \mathrm{m}$ (James \& Findlay 1989). The relative distribution of size classes of potential prey particles were not measured in this study. However, the higher relative proportion of anchovies at the Oregon site means that in general, the schools observed in Oregon were capable of particle feeding on smaller items than schools observed in Monterey Bay, which would be more conducive to dispersing.

Based on our results, we speculate that schooling fish at the Oregon site followed the typical schooling behavior, with dispersal at night in a region where diel vertical migration of zooplankton limited particle feeding during the day while relying on filter feeding on small prey during the day while in schools. During the night, foraging may depend on ambient light as vision limits particle feeding. If light is limited, these fish might rely primarily on filter feeding both day and night. Comparison of daytime and nighttime stomach content of sardine conducted near the Oregon study site found no difference in stomach fullness and no relationship between phytoplankton abundance in the diet and chlorophyll a (chl a) concentrations (Emmett et al. 2005). The same study did find a seasonal and spatial effect on sardine diet composition, with inshore sardines (<150 m isobaths) consuming primarily copepods and phytoplankton but did not investigate the diel pattern of diet composition. To confirm our hypothesis, a future study would be needed to investi- gate the diel patterns of forage fish diet composition simultaneously with the diel schooling behaviors to test if fish are in fact switching feeding modes when transitioning to dispersed behavior at night.

\section{Conclusion}

The sites in this study represent 2 different regions of important commercial fishing grounds for sardines and anchovies in the California Current System. Variability in schooling dynamics of these important commercial species can have significant implications for the fishery. The difference between dispersed individuals and distinct schools or aggregations determines the availability of fish to the fishery and the type of gear that will be most effective at catching them (Fréon \& Misund 1999, Parrish 1999). The timing of fish behavior is also an important factor in capture as well as assessment for management. Sardines and anchovies are typically fished in Monterey Bay and off the Oregon and Washington coasts by purse seine operations. The sardine fishery in Astoria, Oregon, near our study site, fishes primarily during the day, relying on spotter planes to direct boats to the large schools of fish that can be observed at the surface. In Monterey Bay, the fishery on sardines and anchovies occurs during both day and night, with individual vessels making multiple trips per day. These patterns of fishing efforts are consistent with the diel patterns of schooling that were observed for each region.

Water column observations from stationary moorings allowed us to investigate the diel patterns of schooling behavior. The continuous observations from these moorings provided an extensive and unique data set of fish schooling behavior devoid of the effects of avoidance behaviors and a near-surface blind zone that are usually associated with ship-based surveys. By combining these temporal-based observations with spatialbased observations from ships, we were able to obtain new insight into the diel behaviors of schools in their natural habitat. Diel patterns of schooling are dependent on several variables in addition to daylight or night conditions and prey availability may also play a key role in the foraging behaviors for these pelagic fish schools.

Acknowledgements. This work was funded by U.S. Office of Naval Research grant \# N000140510608 and National Oceanic Partnership Program grant \#N000140510669 to K.B-B. C. M. Waluk, J. H. Churnside, R. D. Brodeur, E. D. Brown, J. K. Horne, P. Adam, D. C. Reese, T. J. Cowles, M. A. McManus, D. V. Holliday, T. Guy, M. Litz, and J. Zamon assisted with data collection and data processing. C. Maiden, C. Reichmuth, P. McEhaney, P. Raimondi, and M. Carr provided logistical support in Monterey Bay. W. W. L. Au, C. B. Miller, and 
T. J. Cowles provided equipment used in this study. M. J. Zirbel, C. B. Miller, B. Peterson, C. Morgan, and M. Sutor assisted with the analysis of zooplankton samples. We thank R. Brodeur and D. Reese for providing fish trawl data for the Oregon site, and J. Sullivan and P. Donaghay for providing integrated chlorophyll data from Monterey Bay. Thank you to the captains and crews of the FV 'Frosti,' RV 'New Horizon,' and RV 'Thompson' for their hard work, and especially to the captain and crew of the FV 'Pacific Journey' who donated their time and vessel for mooring deployments off Oregon. L. Ciannelli and 4 anonymous reviewers improved this manuscript through their critical reviews.

\section{LITERATURE CITED}

Axenrot T, Didrikas T, Danielsson C, Hansson S (2004) Diel patterns in pelagic fish behaviour and distribution observed from a stationary, bottom-mounted, and upward-facing transducer. ICES J Mar Sci 61:1100-1104

Azzali M, Buracchi G, Conti S, Gambetti S, Luna M (1985) Relationship between the forms of pelagic fish distribution and nycthemeral periods. A tentative model of behaviour. Oebalia 11:471-488

Barange M (1994) Acoustic identification, classification and structure of biological patchiness on the edge of the Agulhas Bank and its relation to frontal features. S Afr J Mar Sci 14:333-347

Bertrand A, Barbieri M, Gerlotto F, Leiva F, Cordova J (2006) Determinism and plasticity of fish schooling behaviour as exemplified by the South Pacific jack mackerel Trachurus murphyi. Mar Ecol Prog Ser 311:145-156

Blaxter JHS, Hunter JR (1982) The biology of the clupeoid fishes. Adv Mar Biol 20:1-223

Breder CM (1967) On the survival value of fish schools. Zoologica 52:25-40

Brodeur RD, Fisher JP, Emmett RL, Morgan CA, Casillas E (2005) Species composition and community structure of pelagic nekton off Oregon and Washington under variable oceanographic conditions. Mar Ecol Prog Ser 298:41-57

- Cardinale M, Casini M, Arrhenius F, Håkansson N (2003) Diel spatial distribution and feeding activity of herring (Clupea harengus) and sprat (Sprattus sprattus) in the Baltic Sea. Aquat Living Resour 16:283-292

$>$ Cheriton OM, Stacey MT, Steinbuck JV (2009) Physical and biological controls on the maintenance and dissipation of a thin phytoplankton layer. Mar Ecol Prog Ser 378:55-69

Cunha M, Garrido S, Pissarra J (2005) The use of stomach fullness and colour indices to assess Sardina pilchardus feeding. J Mar Biol Assoc UK 85:425-431

Diner N (2001) Correction on school geometry and density: approach based on acoustic image simulation. Aquat Living Resour 14:211-222

Donaghay PL (2004) Profiling systems for understanding the dynamics and impacts of thin layers of harmful algae in stratified coastal waters. Proc 4th Irish Marine Biotoxin Sci Workshop, Marine Institute, Galway, p 44-53

Emmett RL, Brodeur RD, Miller TW, Pool SS, Bentley PJ, Krutzikowsky GK, McCrae J (2005) Pacific sardine (Sardinops sagax) abundance, distribution and ecological relationships in the Pacific Northwest. CalCOFI (Calif Coop Ocean Fish Investig) Rep 46:122-143

Foote KG, Vestnes G, Maclennan DN, Simmonds EJ (1987) Calibration of acoustic instruments for fish density information: a practical guide. Int Coun Explor Sea Coop Res Rep 144, p 1-57

Fréon P, Misund OA (1999) Dynamics of pelagic fish distribu- tion and behaviour: effects on fisheries and stock assessment. Blackwell, Fishing News Books, London

Fréon P, Gerlotto F, Soria M (1996) Diel variability of school structure with special reference to transition periods. ICES J Mar Sci 53:459-464

Garrido S, Marcalo A, Zwolinski J, van der Lingen C (2007) Laboratory investigations on the effect of prey size and concentration on the feeding behaviour of Sardina pilchardus. Mar Ecol Prog Ser 330:189-199

Garrido S, Ben-Hamadou R, Oliveira P, Cunha M, Chicharo $M$, van der Lingen C (2008) Diet and feeding intensity of sardine Sardina pilchardus: correlation with satellitederived chlorophyll data. Mar Ecol Prog Ser 354:245-256

- Graham W, Largier J (1997) Upwelling shadows as nearshore retention sites: the example of northern Monterey Bay. Cont Shelf Res 17:509-532

Holliday DV, Greenlaw CF (2008) Patterns in the fine-scale vertical distributions of zooplankton. AGU Ocean Sciences, Orlando

Hunter J, Nicholl R (1985) Visual threshold for schooling in northern anchovy Engraulis mordax. Fish Bull (Wash DC) 83:235-241

- Huyer A (1983) Coastal upwelling in the California current system. Prog Oceanogr 12:259-284

James A (1987) Feeding ecology, diet and field-based studies on feeding selectivity of the Cape anchovy Engraulis capensis Gilchrist. S Afr J Mar Sci 5:673-692

James A, Findlay K (1989) Effect of particle size and concentration on feeding behaviour, selectivity and rates of food ingestion by the Cape anchovy Engraulis capensis. Mar Ecol Prog Ser 50:275-294

> Kieser R, Mulligan TJ, Richards LJ, Leaman BM (1993) Bias correction of rockfish school cross section widths from digitized echo sounder data. Can J Fish Aquat Sci 50: $1801-1811$

Lasker R (1970) Utilization of zooplankton energy by a Pacific sardine population in the California Current. In: Steele JH (ed) Marine food chains. Oliver \& Boyd, Edinburgh, p 265-284

O'Connell CP (1963) The structure of the eye of Sardinops caerulea, Engraulis mordax, and four other pelagic marine teleosts. J Morphol 113:287-329

> Parrish J (1999) Using behavior and ecology to exploit schooling fishes. Environ Biol Fishes 55:157-181

Parrish JK, Hamner WM (1997) Animal groups in three dimensions, Cambridge University Press, Cambridge

Pitcher TJ, Parrish JK (1993) Functions of shoaling behaviour in teleosts. In: Pitcher TJ (ed) Behavior of teleost fishes. Chapman and Hall, New York, p 363-439

Pitcher TJ, Partridge BL, Wardle CS (1976) A blind fish can school. Science 194:963-965

Radakov DV (1973) Schooling in the ecology of fish. Wiley \& Sons, New York

Robinson CLK (2000) The consumption of euphausiids by the pelagic fish community off southwestern Vancouver Island, British Columbia. J Plankton Res 22:1649-1662

> Rosenfeld L, Schwing F, Garfield N, Tracy D (1994) Bifurcated flow from an upwelling center: a cold water source for Monterey Bay. Cont Shelf Res 14:931-964

Soria M, Freon P, Gerlotto F (1996) Analysis of vessel influence on spatial behaviour of fish schools using a multibeam sonar and consequences for biomass estimates by echo-sounder. ICES J Mar Sci 53:453-458

> Soria M, Bahri T, Gerlotto F (2003) Effect of external factors (environment and survey vessel) on fish school characteristics observed by echosounder and multibeam sonar in the Mediterranean Sea. Aquat Liv Res 16:145-157 
Vabø R, Olsen K, Huse I (2002) The effect of vessel avoidance of wintering Norwegian spring spawning herring. Fish Res 58:59-77

> Weston DE, Andrews HW (1990) Seasonal sonar observations of the diurnal shoaling times of fish. J Acoust Soc Am 87:

Editorial responsibility: Hans Heinrich Janssen, Oldendorf/Luhe, Germany
$673-680$

Zwolinski J, Morais A, Marques V, Stratoudakis Y, Fernandes PG (2007) Diel variation in the vertical distribution and schooling behaviour of sardine (Sardina pilchardus) off Portugal. ICES J Mar Sci 64:963-972

Submitted: September 16, 2009; Accepted: July 30, 2009

Proofs received from author(s): November 7, 2009 